\title{
A Complementary Approach to Flexible Automation
}

\author{
R. Roshardt*, C. Uhrhan*, T. Waefler**, S. Weik** \\ *Institute of Robotics, **Work and Organizational Psychology Unit \\ Swiss Federal Institute of Technology (ETH) Zürich
}

8092 Zürich, Switzerland

Tel: ++41 1632 5553, Fax: ++41 1632 1078,e-mail: roshardt@ifr.mavt.ethz.ch

\begin{abstract}
In the early days of automation the engineer designed the task to be automated in a manner where technical solutions were available. The rest of the work had to be done by the operator. These technically oriented systems failed because they were not flexible and the human had no possibilities to intervene or override the programmed process. In this paper a method for the design of automated, sociotechnical work systems is presented. It is based on a concept of complementary allocation of functions between human operators and machines. The method was used to design a robot system for automated charging of a press brake within a computer integrated sheet metal forming cell. This leads to extended requirements of the technology that are briefly presented.
\end{abstract}

\section{Keywords}

balanced automation, complementary function allocation, flexible press brake automation

\section{INTRODUCTION}

In former times it was tried to increase the flexibility in manufacturing by full automation and computer integration of the production lines. Therefore computer aided design systems (CAD), computer aided planning systems (CAP) and numerical controlled machines (CAM) were used and coupled together by data networks. The problem of such fixed planned production models are that uncertainties, failures and disturbances which occur daily in every factory cannot be handled automatically. These tasks are left to the operator. The result of this automation concept is a so called "CIM-ruin" (CIM - Computer Integrated Manufacturing), where expensive installations do not work because of small errors. New approaches suggest that only with the simultaneous planning of human resources, technology and organization economic automation is possible. This judgement yields to concepts like the "fractal company" (Warnecke, 1993) and the "MTO - Man Technology Organization - approach" (Ulich, 1993). In this paper we describe 
an approach to automating a flexible bending cell according to the global concept of "MTO".

Bending with press brakes is a very flexible manufacturing technology. Multiformed parts can be produced with one press brake and some fixed installed standard tools. In fact, sheet metal bending with press brakes is predestined for low batch sizes. Combined with appropriate automation bended sheet parts become an economic alternative to welded, casted or cutted parts.

Human work at non automated press brakes consists of several tasks: the definition of the bending sequence from workshop drawings, choice and installation of tools, programming the press brake and workpiece handling at the press brake. Nowadays, automation at the planning level is already available - for example CAP-systems that generate bending sequences from a CAD model (e.g. Reissner \& Ehrismann, 1990). Nevertheless, the computer assisted work at press brakes is only semi-automated because the manual feeding of sheets in the press brake is still necessary.

There are already some research projects as well as industrial applications working on automating the charging of press brakes with robots (Uhrhan, 1994). The industrial applications are normaly used for high batch sizes. With decreasing batch sizes and more complex final part shape, advanced robot features like sensor guidance and sensor supported programming are needed. Also interaction of an operator with tasks and decisions must be possible for optimization and to keep the system running.

The planning and valuation of our production system was carried out by a method which is based on a complementary design of sociotechnical systems named KOMPASS (Weik, Grote \& Zölch, 1994; Grote, Weik, Wäfler \& Zölch, in press). The method helps to define which functions should be automated and how they should be automated.

\section{FUNCTION ALLOCATION - BASIC TOPIC IN REALIZING BALANCED AUTOMATION}

Nowadays it seems to be widly accepted, "...that automated systems still are man-machine systems, for which both technical and human factors are important..." (Bainbridge, 1983, 129). That is why in the course of every system design process - especially in those which are concerned with the introduction of automated manufacturing technology - sooner or later the question will arise how functions between operator and machine should be allocated.

Despite the omnipresence of that very central, work psychological and technical question (generally) design methods are only available on a theoretical level but are difficult to apply in practice. What different authors consistently plead for is that "...the correct process for balancing human and machine actions should become an institutionalized part of system design" (Bastl et al., 1991, 19). Very often the technical system is developed first or even exists already. The social system just gets adapted to it, which means that psychological and also organizational aspects which cannot be systematized in the same way are usually not given due regard or even are not taken into consideration at all.

30 years ago Jordan (1963) pointed out already, that for really do justice to human features in a work system one should turn to a complementary view of the relationship between human and machine. Such a view accommodates that the capabilities of human and machine differ also in a qualitative manner, meaning they cannot replace but only complement each other.

In the following sections we intend to show, how this concept of complement - which is cited quite often but still is rather poorly operationalized - might be applied in practice. 


\subsection{The instrument KOMPASS (complementary analysis and design of production tasks in sociotechnical systems)}

KOMPASS wants to provide industrial practitioners (e.g. planners, engineers, production managers, human factors specialists), who are concerned with the development and adaptation of automated production processes. Special attention is paid to the allocation of functions between operator and machine (Grote, 1994; Weik et al., 1994). The project has two main objectives:

(1) Definition, operationalization, and validation of an integrated set of evaluation criteria support complementary system design.

(2) Development of a heuristic which helps multidisciplinary design teams to find and evaluate different kinds of allocation scenarios in a participating manner. Initiation of a learning process which leeds to complementary system design.

Criteria for complementary system design (objective 1) have to cover the three domains: human resources, technology, and organization as demanded by the MTO-approach. Design guidelines which cover the organizational aspect are nowadays widely developed (cf. Ulich, 1994). They demand independent organizational units, interdependent tasks within the organizational unit and the unity of product and organization. Criteria for the analysis, evaluation, and design of humane working conditions have been described in detail by the psychological action regulation and activity theories (e.g. Hacker, 1986; Ulich, 1994). Requirements for humane tasks are, for instance: Completeness, planning and decision making requirements, variety of demands, cooperation requirements, learning possibilities and autonomy.

As far as the technological aspect is concerned, the design of human-machine systems is very often reduced to the design of optimal (i.e. user friendly) interfaces. KOMPASS concentrate more on the question of how to allocate the actual contents of complete working tasks to either human, machine or both (Ulich et al. 1991). Therefore one of the objectives is to develop criteria which enable a design team to evaluate whether an already existing or planned humanmachine system complies with the demands of complementary design. The second objective of KOMPASS is the development of a design heuristic which enables design teams to integrate work psychological findings - such as complementary function allocation - into their activities.

\subsection{Stepwise description of the design process}

A first version of the KOMPASS design heuristic was used to structure the design process of an automated sheet bending press. The design team comprised two computer scientists, one engineer and two work psychologists. Five steps were worked through in rather an iterative than a sequential process!

Step 1: Definition of the primary function and the subfunctions of the planned work system

Step 2: Participatory development of a shared evaluation concept to differentiate between successful and unsuccessful system design

Step 3: Identification of the potential contributions of human operator, technological system and organizational conditions to a successful system performance

Step 4: Discussion and definition of design objectives for each subfunction, focusing on selected evaluation criteria

Step 5: Definition of allocation scenarios for each subfunction 
In the first step the primary function and the subfunctions of the planned work system have to be defined. The work system 'sheet metal bending cell' consists of technical components and human operators. Therefore the fulfilment of the operative system function 'sheet metal forming' depends on the quality of the joint performance of operator and technology. The definitions of the operative function and the subfunctions of the work system are to be made on the system level, i.e. without allocating functions to either human or machine at this early stage of the design process. The functions defined for the automated sheet bending cell are presented in Table 1 , column 1 .

In the second step the design team is asked to charaterize how the planned system should perform. For that purpose the team members should jointly develop and define criteria that allow them to measure the system performance and to compare different scenarios of the planned system. Criteria that have been defined are for instance: profitability/productivity (effectiveness: e.g. quality of process result, efficiency: e.g. quality of process), flexibility/adaptability (fast and easy change of jobs, fast and easy tool setting), reliability/availability, acceptance by operators and usability (easy handling and maintenance).

In step 3 it is discussed which specific contributions to a successful performance of the planned system are provided by the human operator, the technical system and the organizational conditions. The purpose of this step is to direct the attention of the team members towards the qualitatively different influences of human operators, technology and organization to the performance of the work system.

In step 4 it is now to define design objectives for the functions (cf. step1). Based on assumptions about which criteria are the most critical in any design process (Grote, 1994), some of the criteria developed by the research project KOMPASS are selected for further discussion. These are in our case planning and decision-making requirements, transparency, decision authority, and completeness of tasks. The results of this discussion are summarized in Table 1, columns 2-5. It follows a brief description of the criteria:

The criterion planning and decision-making requirements is used to identify those subfunctions with a high potential for planning and decision making. Based on this potential, it should be discussed what consequences it might have for human efficiency if this planning and decision making is not delegated to the operator, but to the technical system or the organization.

Transparency: It has to be discussed how the technical components of the human-machine system have to be designed to enable the operator to understand (cognitive level) what happens "in" the machine he is working with. Additionally it has to be clarified whether the future operator will get the technical opportunity to develop tacit knowledge.

Automation potential and decision authority: In a first step the design team has to mark all those subfunctions whose automation is (at least partly) technically feasible or where a technical support of any kind is possible. In a second step it has to be discussed how the decision authority within these functions should be allocated between human operator and machine.

Completeness of tasks: Each subfunction should be marked, according to it's preparing, planning, executing, controlling and/or maintenance elements. In order to create meaningful and intrinsic motivating working tasks, the future operator should be confronted with a task, that contains all those elements.

In the final step 5 a first variant of an allocation scenario has to be developed. For each subfunction it has to be defined which parts of the function are allocated to the operator, the machine or both of them. If other persons or organizational units are involved their part has also to be described. The variant developed by our design team is presented in Table 1, columns $6-8$. 


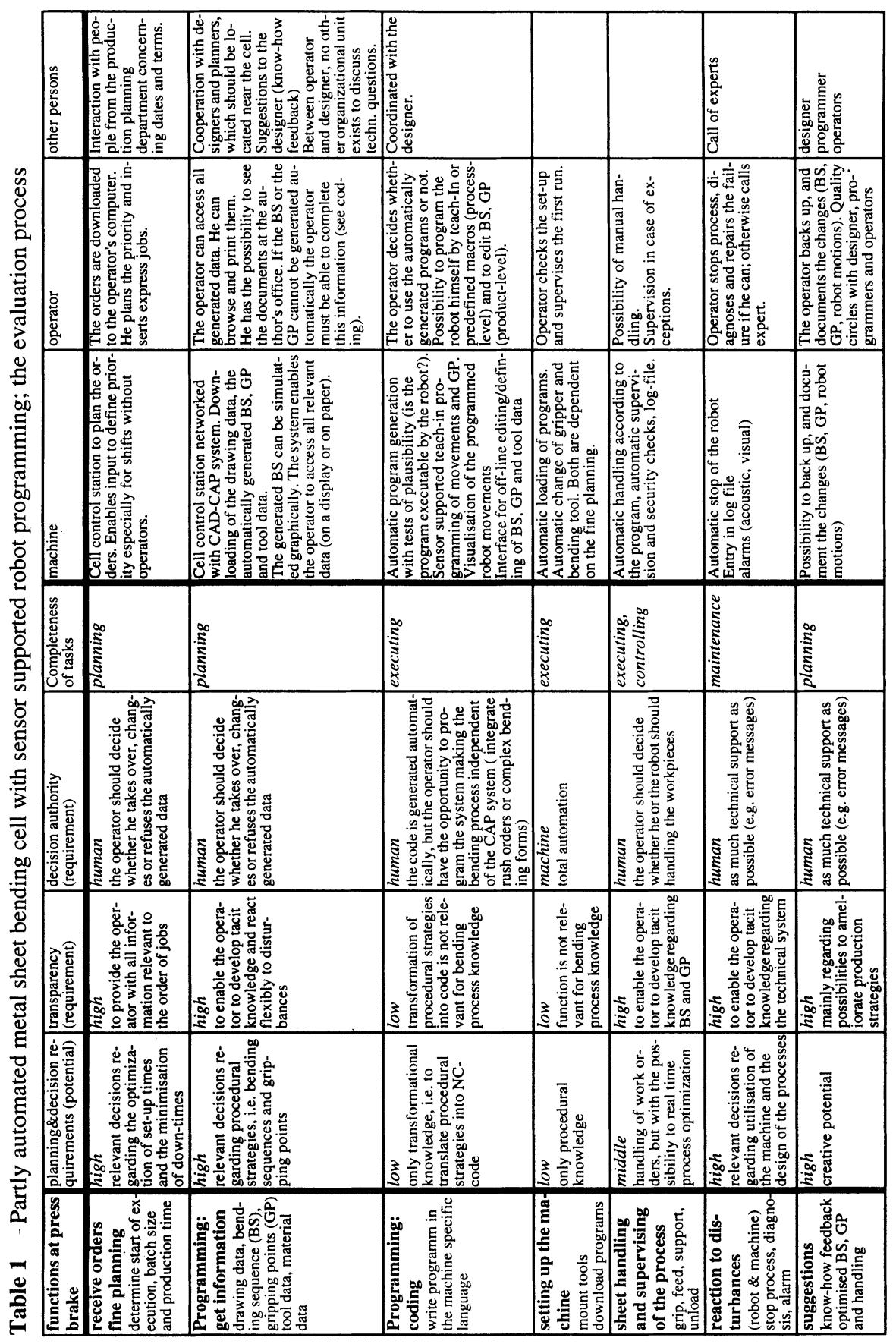




\section{TECHNICAL REQUIREMENTS OF THE ROBOT SYSTEM}

To realize the automation solution as described in Table 1, the technical system must be designed in an appropriate manner. Therefore we designed a robot system including a programming and interaction environment, a special manipulator and a highly integrated sensor gripper.

\section{The user-interface: interaction and programming}

To fulfil the requirements of transparency and decision authority machines and particular the machine controllers must be designed in a way that data access and interaction in tasks and decisions are supported. Therefore a control system was developed which supports efficient robot programming and interaction at four different levels (Uhrhan \& Roshardt, 1994).

The system programming level is highly specific to the robot and is to be used by the robot engineer at development time.

The motion level is the basis for the definition of more application oriented commands. Motions consist of a geometrical and eventually kinematic description of a path to be moved. This level is used to program on-line new robot motions or tune and edit those automatically generated by a CAP-system. The generated paths are presented in a graphical way, see Figure 1 . The point and click interface with drag and drop operations is running on a pen computer with a joystick. This allows the operator to move around in the bending cell and to look at the point of interest while programming in an intuitive way.

At the process level the system is programmed in a macro like language with application oriented high level commands. It uses the same graphical user interface as the motion programming but the level of abstraction is higher. The modular units can be composed into complex tasks. The parameters of the macros may be given from a previous planning level, by teach-in, by the description of sensor values in the goal position or by manual editing at the product level.

At the product level programming is done by describing the product in an appropriate manner. In our case by describing the flat sheet size and the bending sequence for manufacturing the sheet part. Robot programming is carried out automatically with this data and the result can be simulated graphically.
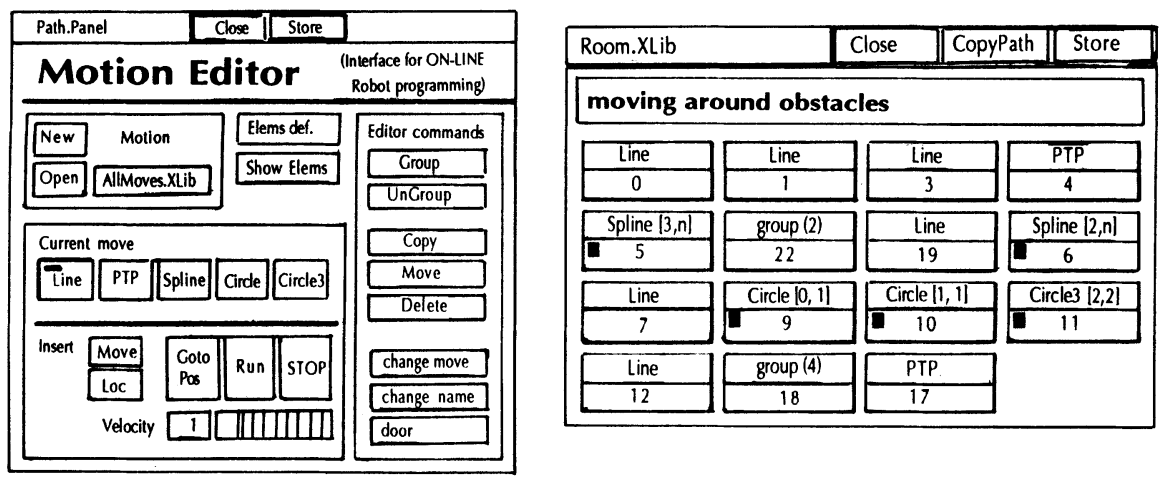

Figure 1 User interface of the motion level programming. 


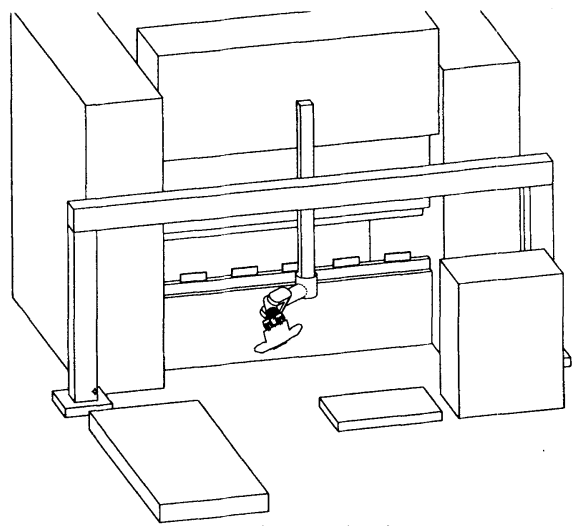

Figure 2 Simulation of the automated press brake.

\section{The manipulator and sensor gripper}

As we had established, automated workpiece handling should be aimed at with the constraint that also manual charging of the press brake should be possible. To support this we designed a robot structure consisting of a gantry robot with two prismatic and four revolute joints (Figure 2). This configuration enables manual sheet handling without any restriction and it reduces the dangerous area in front of the automated press brake.

To guarantee reliable execution of the sheet handling we developed a sensor gripper which perceives the deviations and interactions with the environment. The sensor information is also used to support manual robot programming. For teaching the robot needs only to be moved in the neighbourhood of the destination. The final location is found sensor guided.

\section{CONCLUSION}

KOMPASS is a heuristic for the design of automated, sociotechnical work systems. It is based on a concept of complementary allocation of functions between human operators and machines. The concept's main assumptions enclose the notion that humans and machines can not replace but complete or support each other. Thus the allocation of function must ensure that the human's working task provides him with possibilities to improve and bring in his tacit knowledge. Therefore his task has to be prospectively analysed and assessed according to it's potential planning and decision-making requirements, it's transparency, it's decision authority and it's completeness. The bending cell presented in this paper has been analysed according to the KOMPASS heuristic. Analysing the tasks in advance allows to design the technology in a way to fulfil the needs of flexible function allocation. The main spots in realizing our system for press brake automation are the design of a manipulator, the integration of sensors, the user interface and the programming environment and concept.

The project is part of the "ZIP - Zentrum für integrierte Produktionssysteme" (Centre for Integrated Production Systems), which is composed of several institutes of the ETH. The construction of the forming cell is carried out in cooperation with the Institute for Forming Technology of the ETH. The aspects belonging the operators work are analysed together with the Work and Organisational Psychology Unit. 


\section{REFERENCES}

Bainbridge, L. (1983). Ironies of automation, in Analysis, design and evaluation of manmachine systems (Eds: G. Johannsen \& J.E. Rijnsdorp). Proceedings of the IFAC / IFIP / IFORS Conference Baden-Baden 1982. Pergamon Press, Oxford.

Bastl, W., Jenkinson, J., Kossilov, A., Olmstead, R.A., Oudiz, A. \& Sun, B. (1991). Balance between automation and human actions in NPP operation, in Proceedings of an international symposium of balancing automation and human action in nuclear power plants. International Atomic Energy Agency, Vienna, 11 - 32.

Grote, G. (1994). A participatory approach to the complementary design of highly automated work systems, in Human factors in organizational design and management (Eds. G. Bradley \& H.W. Hendrick). Elsevier, Amsterdam.

Grote, G., Weik, S., Wäfler, T. \& Zölch, M. (in press). Criteria for the complementary allocation of functions in automated work systems and their use in simultaneous engineering projects. International Journal of Industrial Ergonomics.

Hacker, W. (1986). Arbeitspsychologie. Schriften zur Arbeitspsychologie (ed. E. Ulich), Band 41. Huber, Bern.

Jordan, N. (1963). Allocation of functions between man and machines in automated systems. Journal of Applied Psychology, 47 (3), 161 - 165.

Reissner, J. \& Ehrismann, R. (1990). Einsatz von regel- und algorithmenbasierten Verfahren bei der Bestimmung von Biegefolgen. VDI Berichte Nr. 867. VDI-Verlag, Düsseldorf.

Uhrhan, Ch. (1994) Automated Sheet Bending with Press Brakes, in Proc. of the 25th Int. Sym. on Industrial Robots (25th ISIR). 25.-27. April 1994, Hannover.

Uhrhan, Ch. \& Roshardt, R. (1994) User Oriented Robot Programming in a Bending Cell, in Proc. of the Int. Conference on Intelligent Robots and Systems, Munich, Vol.2.

Ulich, E. (1993). CIM - eine integrative Gestaltungsaufgabe im Spannungsfeld Mensch, Technik, Organisation, in CIM - Herausforderung an Mensch, Technik, Organisation, Band 1 ( Eds G. Cyranek \& E. Ulich). vdf, Zürich; Teubner, Stuttgart.

Ulich, E. (1994). Arbeitspsychologie. Verlag der Fachvereine, Zürich; Poeschel, Stuttgart.

Ulich, E., Rauterberg, M., Moll, T., Greutmann, T. \& Strohm, O. (1991). Task orientation and user-oriented dialog design. Int. Journal of Human-Computer Interaction, 3 (2), 117 - 144.

Warnecke, H.J. (1993). The Fractal Company, A Revolution in Corporate Culture. Springer, Berlin.

Weik, S., Grote, G., Zölch, M. (1994). KOMPASS Complementary Analysis and Design of Production Tasks in Sociotechnical Systems. IOS Press.

Weik, S., Grote, G. \& Zölch, M. (1994). KOMPASS: Complementary analysis and design of production tasks in sociotechnical systems, in Advances in agile manufacturing (Eds. P.T. Kidd \& W. Karwowski), IOS Press, Amsterdam, 250 - 253.

\section{BIOGRAPHY}

The authors are working as research assistants at the Institute of Robotics and the Work and Organizational Psychology Unit of the ETH Zurich. R. Roshardt is computer scientist, C. Uhrhan industrial engineer and T. Waefler and S. Weik are work psychologists. All are members of the Centre for Integrated Production Systems (ZIP), of the ETH. 